\title{
Coastal wetland change detection using high spatial resolution KOMPSAT-2 imagery
}

\author{
Wooyeon Sunwoo, Hoang Hai Nguyen, and Minha Choi * \\ Environment and Remote Sensing Laboratory, Department of Water Resources, Graduate School of Water Resources, \\ Sungkyunkwan University, Suwon, Republic of Korea
}

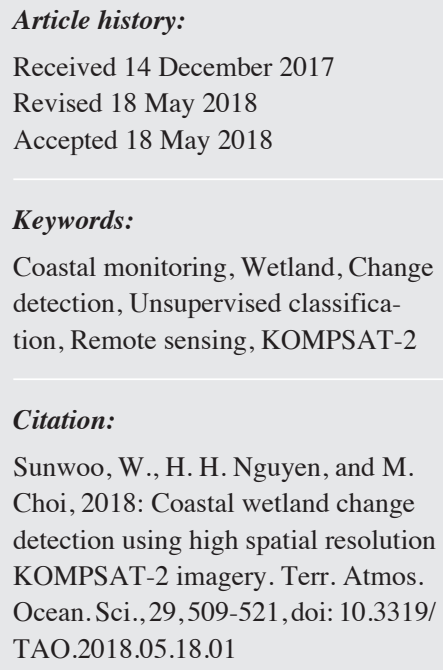

Citation:

Sunwoo, W., H. H. Nguyen, and M. Choi, 2018: Coastal wetland change detection using high spatial resolution KOMPSAT-2 imagery. Terr. Atmos. Ocean. Sci., 29,509-521, doi: 10.3319/ TAO.2018.05.18.01

\begin{abstract}
Coastal wetlands store terrestrial carbon and conserve biodiversity, thus playing an essential ecological role. Reliable regional-scale assessments of wetland dynamics, such as analysis of land use and land cover (LULC), and coastal monitoring, provide important hydrographical and socio-geographical information. Remote sensing images, such as Earth Observation satellite data, are useful for examining temporal LULC changes and providing environmental monitoring data. This study presents a method of mapping and monitoring changes in coastal LULC using classified multispectral images acquired by the Korea Multi-Purpose Satellite-2 (KOMPSAT-2). Wetland changes are monitored in three different protected tidal flats areas on the coastal boundary of the Korean Peninsula with the Yellow Sea, for the period of 2008 - 2015. High overall accuracy and Kappa coefficient values for the accuracy assessment indicate the suitability of LULC classification using high spatial resolution KOMPSAT imagery, even when an unsupervised classification approach is adopted. The LULC maps were analyzed and evaluated using post-classification change detection methods. Results showed spatial decreases of 6 and 20\% for mixed forest and wetlands in the Gyeonggi area, respectively, but no significant changes over time for Jeonbuk and Jeonnam. There was a $12 \%$ increase in developed areas for Gyeonggi but only 1.9 and $6 \%$ for Jeonbuk and Jeonnam, respectively. LULC change is thus easily identified through a pixel-based analysis of multispectral KOMPSAT-2 images over time. Such data are useful for environmental and policy managers when developing advanced coastal management strategies.
\end{abstract}

\section{INTRODUCTION}

Coastal wetlands play an essential role in promoting ecosystem biodiversity by providing natural habitats for a wide variety of species (Gibbs 2000; Klemas 2013). From an environmental perspective, coastal wetlands are important contributors to global carbon sequestration, flood and coastal erosion mitigation, and water quality improvement. Wetlands comprise a biodiversity-rich and dynamic ecosystem and are a repository of natural resources that are always hydrated by the natural environment. The shape of wetlands changes over time, and they are sensitive to land use changes and vulnerable to the effects of climate change, sea levels rise, and changes in tidal patterns (Gorham 1991; Michishita et al. 2012; Allen et al. 2013). Improving our un-

\footnotetext{
* Corresponding author

E-mail:mhchoi@skku.edu
}

derstanding of different wetland features can contribute to determining sustainable strategies for preserving and monitoring wetlands under various environmental effects (Klemas 2013; Dronova 2015). However, wetlands have experienced severe and rapid degradation in recent decades, with more than $50 \%$ of global wetlands have disappeared, which indicates the need for continuous and effective monitoring of the remaining ecosystems (Michishita et al. 2012).

Identifying wetland regions and their ecological features via a land use and land cover (LULC) mapping methods is potentially a valuable monitoring technique, as traditional field-based surveying is costly and time-consuming. Furthermore, field surveys for coastal monitoring are generally conducted only in limited areas, as a large amount of data are required to analyze erosion and accretion changes over time, and it is difficult to specify the time of the 
survey (Hussain et al. 2013; Klemas 2013). In addition to the advances made in remote sensing technology, multispectral satellite imagery has recently emerged as an effective alternative to conventional field surveying. Remote sensing can provide timely and accurate geospatial information at a regional and global scale; it has thus rapidly become a focus of research and is used in practical applications (Adam et al. 2014; Moser et al. 2016). This digital detection technique identifies real-world changes based on the differences between pixels in images taken on two (or more) separate occasions. As such, remotely sensed data are being used in a wide variety of environmental studies (Tian et al. 2014). Landsat images are commonly used to detect changes due to the existence of long-term data sets and near-nadir observations (Zhu and Woodcock 2014). Braud and Feng (1998) identified the Louisiana coastline via threshold level slicing and image classification techniques using Landsat Thematic Mapper (TM) imagery, and Li and Damen (2010) combined the use of Landsat and Satellite Pour l'Observation de la Terre (SPOT) to examine variations in coastline morphology over time caused by extensive harbor construction and advancing land reclamation in the estuary. Despite their advantages, Landsat images have a relatively coarse spatial resolution of $30 \mathrm{~m}$, and sometimes have problems in accurately characterizing changes that occur within wetland regions. This spatial resolution becomes more significant when extremely accurate image analysis is required (Huang and Friedl 2014).

Recently developed, high spatial resolution $(\leq 5 \mathrm{~m})$ multispectral satellites provide significantly better LULC monitoring at higher order thematic levels (Stroppiana et al. 2002). The three high-resolution sensors that are commonly utilized for such work are IKONOS-2 (Space Imaging Inc., launched in 1999), Quickbird-2 (DigitalGlobe Inc., launched in 2001), and Orbview-3 (ORBIMAGE Inc., launched in 2003). These multispectral sensors produce imagery with a spatial resolution of nearly $4 \mathrm{~m}$, which is far superior to that of medium resolution sensors (i.e., 20 - $250 \mathrm{~m}$ ). Data produced by these high-resolution satellites are not only useful for accurately assessing coastal wetlands (Yagoub and Kolan 2006; Adam et al. 2014; Monteys et al. 2015), but also assist in gaining an understanding of the impacts of interactions between natural and anthropogenic processes (Lee and Shan 2003). Korea Multi-Purpose Satellite-2 (KOMPSAT-2), launched in 2006, is also a high spatial resolution satellite with 4-m resolution multispectral bands. It contributes to the diversity of high spatial resolution satellite sensors and is expected to be incorporated in long-term management of water resources as well as coastal wetlands. However, only a few studies have used KOMPSAT-2 images for mapping wetland regions (Rapinel et al. 2015; Nguyen et al. 2017), it is therefore necessary to assess the potential application of this novel satellite in coastal wetlands. The results of this study would subsequently motivate other researchers to compare
KOMPSAT- 2 with other remote sensing satellite sensors as well as integrate its use for improving coastal wetland management (Guo et al. 2017). Moreover, along with the high global interest in wetland monitoring with regard to environmental and social impacts (Rundquist et al. 2001), the utility of KOMPSAT-2 data can provide intensive information on wetland changes due to various environmental disasters and anthropogenic activities.

To the authors' knowledge, this is the first study that utilizes a change detection technique with KOMPSAT-2 data to enable regional-scale, quantitative monitoring of coastal wetlands. Three regions with daily minimum to maximum tidal ranges were selected for the study, all of which are located along the west coast of the Korean Peninsula where it meets the Yellow Sea. KOMPSAT-2 images were initially classified using an unsupervised classification method, and thematic maps were then used to detect changes in the three wetland areas according to use of a post-classification comparison approach. The three main purposes of this study are to: (1) review classification-based change detection approaches for use in monitoring coastal wetlands on the Korean Peninsula; (2) assess the potential application of high spatial resolution KOMPSAT-2 imagery using unsupervised classification and post-classification comparison change detection approaches; and (3) analyze and evaluate changes in various coastal wetland conditions in the Korean Peninsula that are associated with impacts of regional human activities and urbanization. It is considered that the results of this study, which show detailed temporal changes in coastal wetlands, will be useful for regional land use managers when formulating improved environmental management controls.

\section{METHODS}

Multispectral KOMPSAT-2 images are available for use in monitoring the coastal wetlands on the Korean Peninsula. Historical data for use in assisting coastal management are often limited or nonexistent in many coastal areas; therefore, image sources at a high spatial resolution provided by remote sensing offer a valuable opportunity to determine the current extent of coastal wetlands and to detect changes therein. The procedure of this study is shown in Fig. 1.

\subsection{Study Areas}

The Korean Peninsula is surrounded by the Yellow Sea and the East China Sea. In this study, three separate regions (Gyeonggi, Jeonbuk, and Jeonnam; Fig. 2) on the western coastline adjacent to the Yellow Sea were studied using data from 2008 to 2015. These areas were chosen because they experience daily minimum and maximum tidal ranges. Each regions contains an area of wetland that was designated as protected in the 2000s by the integrated Coastal 


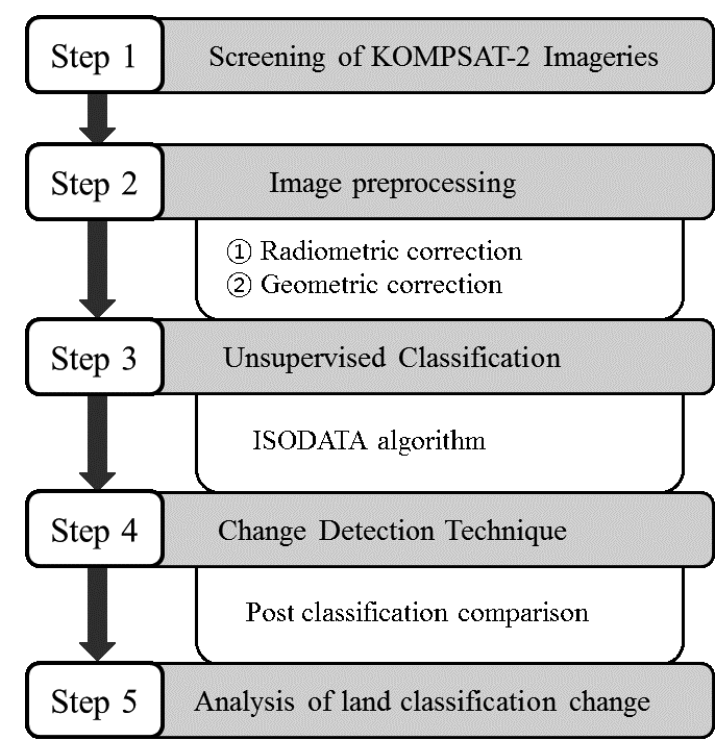

Fig. 1. Procedure of this study.

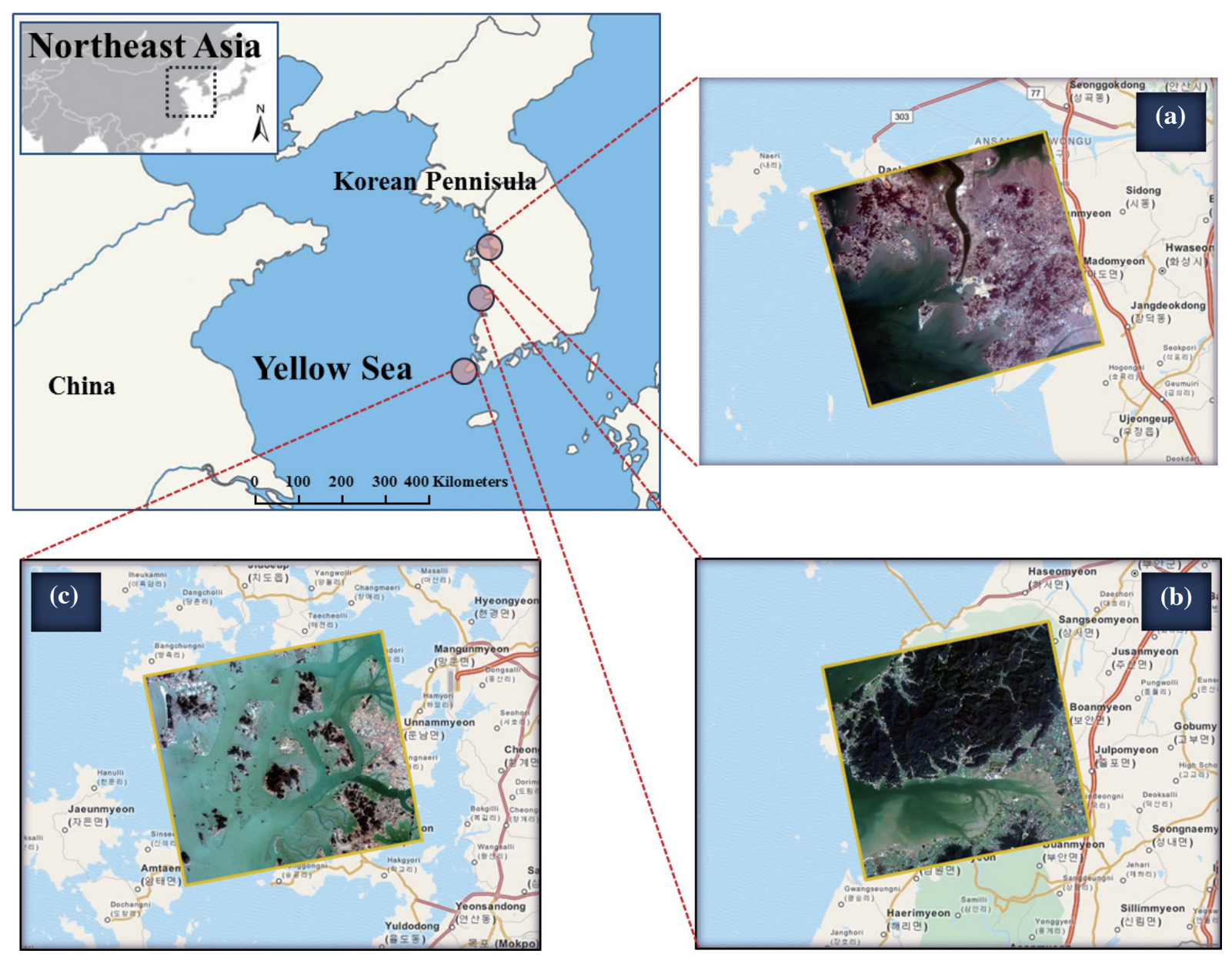

Fig. 2. Locations of the three study areas for KOMPSAT-2 image analysis in the coastal zone of the Yellow Sea, Korean Peninsula. 
Management Plan of the Ministry of Environment, South Korea. The Daebudo wetland is located in the Gyeonggi region, and it spans approximately $10.6 \mathrm{~km}$ along the coastline. It hosts a wide variety of ecosystems, and is a habitat for migratory birds, rare species of crab, mollusks, and fish. The Julpoman and Gochang coastal wetlands are both located in Jeonbuk, and span areas of 4.9 and $10.4 \mathrm{~km}^{2}$, respectively. These wetlands are of high conservation value and both exhibit extensive biodiversity. The Jeongdo coastal wetland is located in Jeonnam and covers a total area of $31.3 \mathrm{~km}^{2}$. Tidal flats located along Korea's western coast are well developed owing to the macro tidal range $(>4 \mathrm{~m})$ and the very gentle bottom slope angle.

\subsection{KOMPSAT-2}

Korea initiated a space program in 1990 and successfully launched its first microsatellite into the Earth's orbit in 1992, followed by scientific sounding rockets in 1993 (Kim 1999). The first Korean Multipurpose Satellite (KOMPSAT-1) was launched on 21 December 1999 and completed its official mission in 2008. It was succeeded by KOMPSAT-2, which was launched in 2005 with multispectral high spatial resolution images provision (on a 1-m grid with its panchromatic band, and on a 4-m grid for multi-spectral scenes on a $15-\mathrm{km}$ wide swath). Basic information of KOMPSAT-2 satellite sensor is shown in Table 1. KOMPSAT-2 level $1 \mathrm{R}$ provides ephemeris data, including the satellite's position, velocity, and attitude angle; this allows for direct geo-registration, and provides rational polynomial coefficients (RPC) for replacement sensor models (Oh et al. 2013). The image quality of KOMPSAT-2 data depends on the combined use of the on-board satellite system and the data-processing system at a ground station. Radiometric and geometric corrections were conducted for the image preprocessing of KOMPSAT-2 images (Nguyen et al. 2017).

High temporal resolution satellite images are preferentially used as the primary source in geo-positioning as they offer a wide coverage, a short revisit time, and an appropriate spatial resolution. Jeong et al. (2015) examined positioning accuracy in detail using ground points generated from IKONOS imagery. In this study, two images collected from the KOMPSAT-2 satellite for each of the three study areas
(Gyeonggi, Jeonbuk, and Jeonnam) were used as input data. High quality, cloud-free KOMPSAT-2 images with the corresponding tide conditions were selected (Table 2). The detailed information on the acquisition time and metadata of each image was provided by the Arirang Satellite Image Search \& Order System (http://arirang.kari.re.kr). The tide prediction time was sourced from the website (http:// badatime.com) maintained by the National Oceanographic Research Institute.

\subsection{Land Cover and Land Use Classification}

The LULC maps used for wetland change detection studies can be obtained by applying the classification methods for the remotely sensed images, which categorizes the pixels into different classes. Generally, two main approaches can be used to generate thematic maps: based on supervised and unsupervised classification. The fundamental difference between these two classification techniques is that while the training samples with known classified categories are necessary and regarded as essential input data for the supervised classification, they are not required for the unsupervised one, which automatically groups pixels with similar spectral values into one category based on the

Table 1. Description of KOMPSAT-2 satellite sensor specifications.

\begin{tabular}{c|c|c}
\hline \multicolumn{2}{c|}{ Features } & KOMPSAT-2 \\
\hline \multirow{4}{*}{ Spectral Bands } & Panchromatic & $0.50-0.90 \mu \mathrm{m}$ (Black and White) \\
& MS1 & $0.45-0.52 \mu \mathrm{m}$ (Blue) \\
& MS2 & $0.52-0.60 \mu \mathrm{m}$ (Green) \\
& MS4 & $0.63-0.69 \mu \mathrm{m}$ (Red) \\
& Panchromatic & $1 \mathrm{~m}$ \\
Spatial Resolution & Multispectral & $4 \mathrm{~m}$ \\
\hline \multicolumn{2}{c|}{ Temporal Resolution } & 14 days \\
\hline \multicolumn{2}{c|}{ Swath Width } & 15 km \\
\hline \multicolumn{2}{c}{ Orbit } & Sun-synchronous \\
\hline \multicolumn{2}{c|}{ Altitude } & 685 km (nadir)
\end{tabular}

Table 2. Description of KOMPSAT-2 multispectral image data acquisition parameters.

\begin{tabular}{c|c|c|c|c|c}
\hline \multirow{2}{*}{ Study area } & \multirow{2}{*}{ Protected tidal flats } & \multicolumn{2}{|c|}{ Image date } & \multirow{2}{*}{ Cloud condition } & \multirow{2}{*}{ Tide condition } \\
\cline { 3 - 4 } & & $\boldsymbol{t 1}$ & $\boldsymbol{t} 2$ & & Low tide \\
\hline Gyeonggi & Daebudo & 3 October 2009 & 4 April 2015 & & Cloud - free \\
Jeonbuk & Julpoman and Gochang & 5 April 2009 & 4 October 2014 & Low tide \\
Jeonnam & Jeongdo & 6 August 2008 & 15 January 2014 & & Low tide \\
\hline
\end{tabular}


computer's clustering algorithm (Ozesmi and Bauer 2002). The benefits of unsupervised classification are that it can be performed easily without training data, thus saving the computation time from the training phase; additionally, the products of the classification maps can be automatically generated even with a large number of used clusters. Moreover, in terms of wetland-related studies, unsupervised classification has shown an outstanding performance due to the concordance of natural regions (Ozesmi and Bauer 2002). Consequently, the unsupervised classification method is an effective tool to produce high-quality classified images when training data are unavailable or difficult to obtain. In this study, we employed two commonly used unsupervised classification methods, the K-means, proposed by MacQueen (1967), and the Interactive Self-Organizing DATa Analysis (ISODATA), introduced by Ball and Hall (1965), to generate thematic maps, which were then used as input data for the wetland change detection technique.

\subsection{Change Detection Technique}

One of the most common approaches used for change detection is to conduct a post-classification comparisons (Foody 2002; Al-doski et al. 2013). In particular, this technique allows classification that multi-temporal images can be independently categorized to generate thematic maps, which can subsequently be used to compare classification types and identify changes that have occurred on a pixel-bypixel basis. In particular, the use of multi-temporal separately classified images for post-classification comparison can reduce the variation in normalizing atmospheric and sensor effects for the data collected at different dates (Singh 1989). Nonetheless, post-classification comparison techniques have certain key limitations. For example, the accuracy of results derived from the method depends on the quality of each individually classified image (Lu et al. 2004); therefore, incorrect results can be produced when using multitemporal or multi-sensor images (Foody 2002; Al-doski et al. 2013) that require calibration from training datasets to provide accuracy and completeness (Hussain et al. 2013). In this study, images with high spatial and temporal resolution (containing 0\% cloud cover) were acquired from KOMPSAT-2 to analyze the coastal wetland change detection.

\subsection{Accuracy Assessment}

An accuracy assessment of the LULC classification, which compares the classified images with ground-truth data, were investigated herein, to evaluate the accuracy and suitability of different classification methods in generating thematic maps. In general, the reliability of an accuracy assessment primarily depends on the quality of the reference data, implying that choosing appropriate ground-truth data with a similar location and collection time as the classified images is an important step prior to conducting the classification process. Reference images can be extracted from high-resolution aerial photograph interpretations, other satellite images, or in-situ measurements using geographic information system (GIS) data. In this study, ground-truth images were generated manually from original images using the ground-truth regions of interest (ROI), first-hand field observations, and land cover reference maps of each of the three study areas (Baraldi et al. 2005).

In this study, we conducted an accuracy assessment based on the error matrix method also known as the confusion matrix (Moser et al. 2016). The fundamental indicators of accuracy included within the error matrix are the overall accuracy (OA), which is calculated from the ratio of correctly classified pixels to the total number of pixels, and the Kappa efficiency $\left(K_{\text {hat }}\right)$, which reflects the difference between the actual agreement and the agreement expected by chance (Cohen 1960).

In addition, both the producer's accuracy (PA), which represents the errors of omission, and the user's accuracy (UA), which represents the errors of commission, were calculated to determine the accuracy for each category of the LULC classifcation. Anderson et al. (1976) proposed that a good classification must meet the classification criteria with OA is over $85 \%$. In this study, more reliable classified maps, which employed the K-means and ISODATA unsupervised classification methods, were selected for change detection in the coastal wetland study regions.

\section{RESULTS}

The unsupervised classification procedure implemented in this study involved the designing clusters based on inherent similarities within the dataset, and then conducting a subsequent assessment of classification results using a change detection technique. Images taken at low tide condition were preferentially chosen in each study area to facilitate the examination of wetland dynamics. These images were obtained during 2009 and 2015 in Gyeonggi, 2009 and 2014 in Jeonbuk, and 2008 and 2014 in Jeonnam.

\subsection{Land Use and Land Cover Classification Maps}

The results of the LULC analysis for each study area are shown as classification maps in Fig. 3, with the data summarized in Table 3. The classification was performed using ENVI 5.2 $2^{\mathrm{TM}}$ software by Harris Geospatial Solutions for a maximum of thirty iterations, which allowed a convergence threshold of $99.99 \%$. Several factors that may have affected the performance and sensitivity of each selected algorithm were examined using trial and error. The classification results confirmed that both the ISODATA and K-means algorithms showed reliable performances for KOMPSAT-2 data. No remarkable differences were found in the results of 

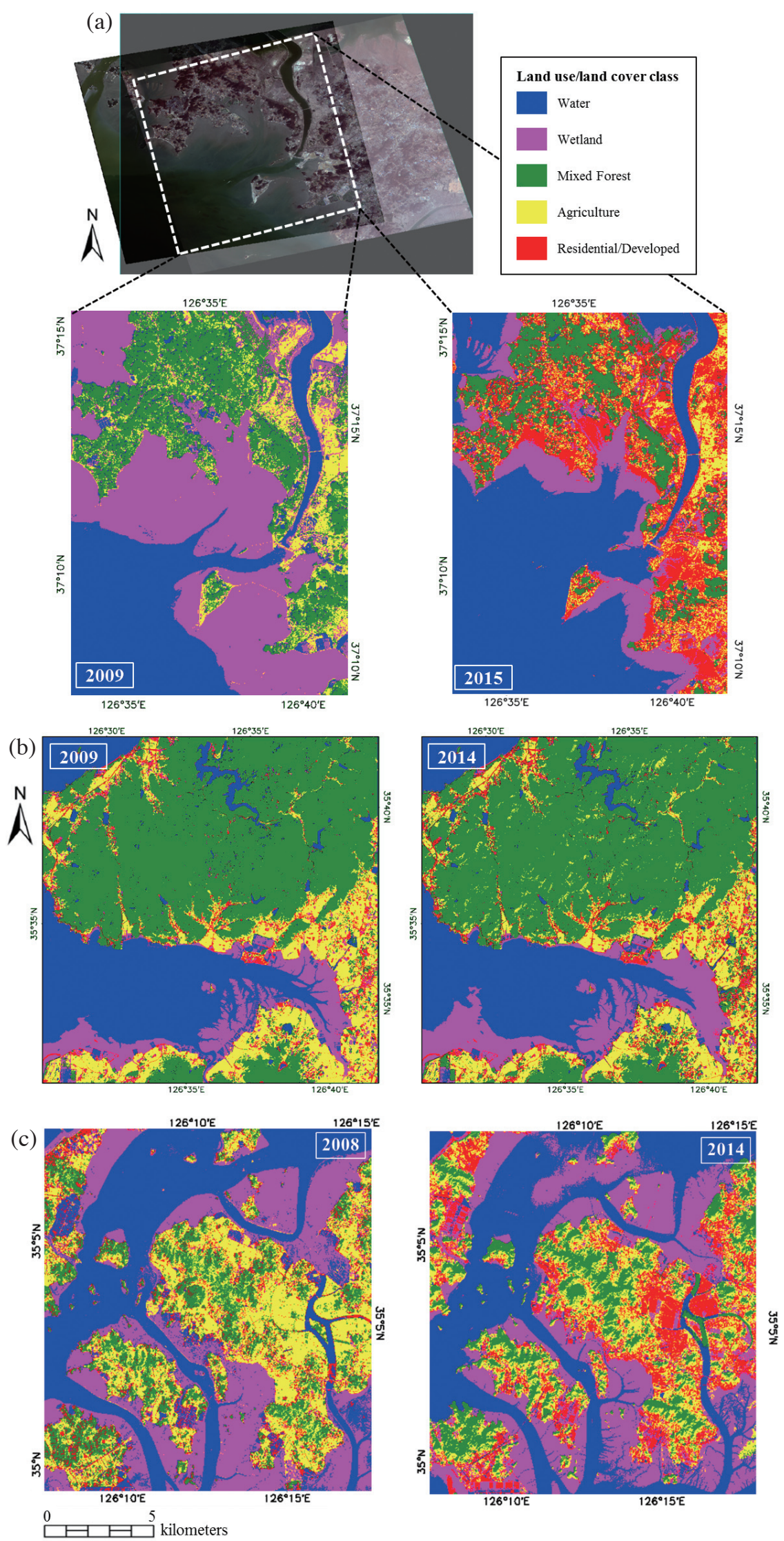

Fig. 3. Results of the land use and land cover classification using five major land cover classes derived from KOMPSAT-2: (a) Gyeonggi from 2009 to 2015; (b) Jeonbuk from 2009 to 2014; and (c) Jeonnam from 2008 to 2014. The spatial distributions of land use and land cover can explain the regional change pattern and differences with time. 
Table 3. Summary of unsupervised land use and land cover classification results from KOMPSAT-2.

\begin{tabular}{|c|c|c|c|c|c|c|}
\hline (a) Gyeonggi & \multicolumn{3}{|c|}{2009} & \multicolumn{3}{|c|}{2015} \\
\hline Class name & Pixel count & Area $\left(\mathrm{km}^{2}\right)$ & Percentage $(\%)$ & Pixel count & Area $\left(\mathrm{km}^{2}\right)$ & Percentage $(\%)$ \\
\hline Water & 2266900 & 36.27 & 22.97 & 3841647 & 61.47 & 39.00 \\
\hline Wetland & 3236686 & 51.79 & 32.80 & 1375830 & 22.01 & 13.97 \\
\hline Mixed Forest & 1941871 & 31.07 & 19.68 & 1320133 & 21.12 & 13.40 \\
\hline Agriculture & 1334482 & 21.35 & 13.52 & 1010400 & 16.17 & 10.26 \\
\hline Residential/Developed & 1088697 & 17.42 & 11.03 & 2301529 & 36.82 & 23.37 \\
\hline Total & 9868636 & 157.90 & 100.00 & 9849539 & 157.59 & 100.00 \\
\hline (b) Jeonbuk & \multicolumn{3}{|c|}{2009} & \multicolumn{3}{|c|}{2014} \\
\hline Class name & Pixel count & Area $\left(\mathrm{km}^{2}\right)$ & Percentage (\%) & Pixel count & Area $\left(\mathrm{km}^{2}\right)$ & Percentage (\%) \\
\hline Water & 3414509 & 54.63 & 23.64 & 2944983 & 47.12 & 20.39 \\
\hline Wetland & 1377149 & 22.03 & 9.53 & 1570723 & 25.13 & 10.88 \\
\hline Mixed Forest & 6922179 & 110.75 & 47.93 & 6981594 & 111.71 & 48.34 \\
\hline Agriculture & 2182671 & 34.92 & 15.11 & 2117075 & 33.87 & 14.66 \\
\hline Residential/Developed & 546737 & 8.75 & 3.79 & 828870 & 13.26 & 5.74 \\
\hline Total & 14443245 & 231.09 & 100.00 & 14443245 & 231.09 & 100.00 \\
\hline (c) Jeonnam & \multicolumn{3}{|c|}{2008} & \multicolumn{3}{|c|}{2014} \\
\hline Class name & Pixel count & Area $\left(\mathrm{km}^{2}\right)$ & Percentage $(\%)$ & Pixel count & Area $\left(\mathrm{km}^{2}\right)$ & Percentage (\%) \\
\hline Water & 3615940 & 57.86 & 30.56 & 3469625 & 55.51 & 29.32 \\
\hline Wetland & 3075401 & 49.21 & 25.99 & 3378047 & 54.05 & 28.55 \\
\hline Mixed Forest & 1619121 & 25.91 & 13.68 & 1487232 & 23.80 & 12.57 \\
\hline Agriculture & 2645481 & 42.33 & 22.36 & 1937872 & 31.01 & 16.38 \\
\hline Residential/Developed & 876361 & 14.02 & 7.41 & 1559528 & 24.95 & 13.18 \\
\hline Total & 11832304 & 189.32 & 100.00 & 11832304 & 189.32 & 100.00 \\
\hline
\end{tabular}

both methods when using $15 \mathrm{~km}^{2}$ images with high temporal resolution. Therefore, the thematic maps generated using the ISODATA algorithm, which is generally known as fine tuning through the segmentation and merging of clusters (Bahadur 2009; Kassawmar et al. 2016), were selected for further analysis. The LULC classification procedure initially produced numerous different land-cover classes, but finally only the five most important ones (water, wetland, mixed forest, agriculture, and residential/developed land) were utilized in further investigation. Parts of Gyeonggi and Jeonnam images overlapped due to the different positions used to takes each photograph. Table 3 shows the results of a classification comparison between older (2008 or 2009) and more recent (2014 or 2015) KOMPSAT-2 images. Pixel LULC classification of the 2009 Gyeonggi image was as follows: $32.80 \%$ of all image pixels are classified as wetland, $22.97 \%$ as water, $19.68 \%$ as mixed forest, $13.52 \%$ as agriculture, and $11.03 \%$ as residential/developed. In 2015, the LULC distribution was $39.00 \%$ water, $13.97 \%$ wetland, $13.40 \%$ mixed forest, $10.26 \%$ agriculture, and $23.37 \%$ resi- dential/developed. A small number of misclassified pixel values did not perfectly match the classification criteria.

Pixel LULC classification of the 2009 Jeonbuk image was as follows: $23.68 \%$ water, $9.53 \%$ wetland, $47.93 \%$ mixed forest, $15.11 \%$ agriculture, and $3.79 \%$ residential/ developed. LULC classification of the 2014 image showed an overall difference of $\sim 0.5-3.0 \%$, indicating that no significant changes in land use occurred during these years. Figure $3 \mathrm{~b}$ shows similar results for five classes with 5-year intervals between each acquisition. In Jeonnam, agriculture decreased by $\sim 6 \%$, while residential/developed areas increased by $6 \%$. No other classes showed any significant change between 2008 and 2014.

\subsection{Validation of Land Classification}

An accuracy assessment was conducted for the unsupervised classification using KOMPSAT data captured at Gyeonggi, Jeonbuk, and Jeonnam during 2008 - 2015 (Table 3). All six classified images showed reasonable 
results, with the OA ranging from 87.6 to $95.4 \%$, and $\mathrm{K}_{\text {hat }}$ ranging from 0.82 to 0.88 , demonstrating a strong agreement between the obtained thematic maps and the accuracy criterion for LULC classification (with $\mathrm{OA} \geq 85 \%$ ) (Anderson et al. 1976). The best OA was recorded at Gyeonggi (95.4 and $94.04 \%$ for the 2009 and 2015 images, respectively), followed by Jeonnam ( 88.7 and $91.3 \%$ for the 2008 and 2014 images, respectively), and Jeonbuk (90.04 and 87.6\% for the 2009 and 2014 images, respectively). However, as neither OA nor $\mathrm{K}_{\text {hat }}$ values show the reliability of each individual class, both PA and UA values were also reported. Almost all classes exhibited high PA and UA values in each of the three study areas (Table 4). In particular, the wetland class had a consistently high accuracy during 2008 - 2015, with values ranging from 78.5 to $100 \%$ (PA) and 79.8 to 99.3\% (UA). However, the residential/developed class generally had a medium-to-low accuracy, especially for Jeonnam in 2008 (PA: 7.35\%) and 2014 (UA: 5.99\%).

\subsection{Change Detection Analysis}

Change detection analysis was conducted using pixelbased remotely sensed images to precisely identify where land use changes had occurred over a specific period of time. Classified areas were transferred to two-dimensional arrays for calculating the number of pixels. LULC changes in the three study areas were compared (Fig. 4). The spatial distribution of Gyeonggi showed that wetland and developed areas were the dominant LULC classes: wetland areas showed a general decrease of $30 \mathrm{~km}^{2}$, equal to $\sim 19 \%$ of the total area $\left(158 \mathrm{~km}^{2}\right)$, while residential area increased by $20 \mathrm{~km}^{2}$. Water was classified as covering $\sim 23$ and $\sim 39 \%$ of the total area in 2009 and 2015, respectively. In Jeonbuk, the residential area increased by $4.5 \mathrm{~km}^{2}$ and the spatial extent of open water decreased by $7.5 \mathrm{~km}^{2}$ from 2008 to 2014 . There was an average change in land use of $\sim 1.48 \%$ during this period. These results imply that no significant impact from the external

Table 4. Accuracy assessment of the land use and land cover classification for each of the three study areas.

\begin{tabular}{|c|c|c|c|c|c|c|c|c|c|c|c|c|}
\hline & \multicolumn{4}{|c|}{ Gyeonggi } & \multicolumn{4}{|c|}{ Jeonbuk } & \multicolumn{4}{|c|}{ Jeonnam } \\
\hline & \multicolumn{2}{|c|}{3 October 2009} & \multicolumn{2}{|c|}{4 April 2015} & \multicolumn{2}{|c|}{5 April 2009} & \multicolumn{2}{|c|}{4 October 2014} & \multicolumn{2}{|c|}{6 August 2008} & \multicolumn{2}{|c|}{15 January 2014} \\
\hline & PA $(\%)$ & UA $(\%)$ & PA $(\%)$ & UA $(\%)$ & PA $(\%)$ & UA $(\%)$ & PA $(\%)$ & UA $(\%)$ & PA $(\%)$ & UA $(\%)$ & PA $(\%)$ & UA $(\%)$ \\
\hline Water & 100.0 & 99.9 & 100.0 & 100.0 & 100.0 & 91.5 & 100.0 & 97.3 & 100.0 & 97.9 & 100.0 & 98.7 \\
\hline Wetland & 100.0 & 94.8 & 100.0 & 98.9 & 78.5 & 83.5 & 100.0 & 79.8 & 99.1 & 99.3 & 99.2 & 96.6 \\
\hline Mixed Forest & 99.2 & 91.9 & 100.0 & 88.5 & 86.4 & 93.3 & 90.8 & 97.1 & 53.6 & 69.7 & 98.9 & 99.8 \\
\hline Agriculture & 86.1 & 92.2 & 86.0 & 83.1 & 81.5 & 93.6 & 72.7 & 81.3 & 83.3 & 71.6 & 39.5 & 90.9 \\
\hline Residential/Developed & 42.5 & 96.7 & 48.4 & 64.5 & 52.2 & 63.1 & 35.6 & 35.2 & 7.35 & 39.0 & 52.5 & 5.99 \\
\hline OA (\%) & \multicolumn{2}{|c|}{95.4} & \multicolumn{2}{|c|}{94.04} & \multicolumn{2}{|c|}{90.04} & \multicolumn{2}{|c|}{87.6} & \multicolumn{2}{|c|}{88.7} & \multicolumn{2}{|c|}{91.3} \\
\hline Kappa Coefficient & \multicolumn{2}{|c|}{0.93} & \multicolumn{2}{|c|}{0.92} & \multicolumn{2}{|c|}{0.85} & \multicolumn{2}{|c|}{0.82} & \multicolumn{2}{|c|}{0.85} & \multicolumn{2}{|c|}{0.88} \\
\hline
\end{tabular}
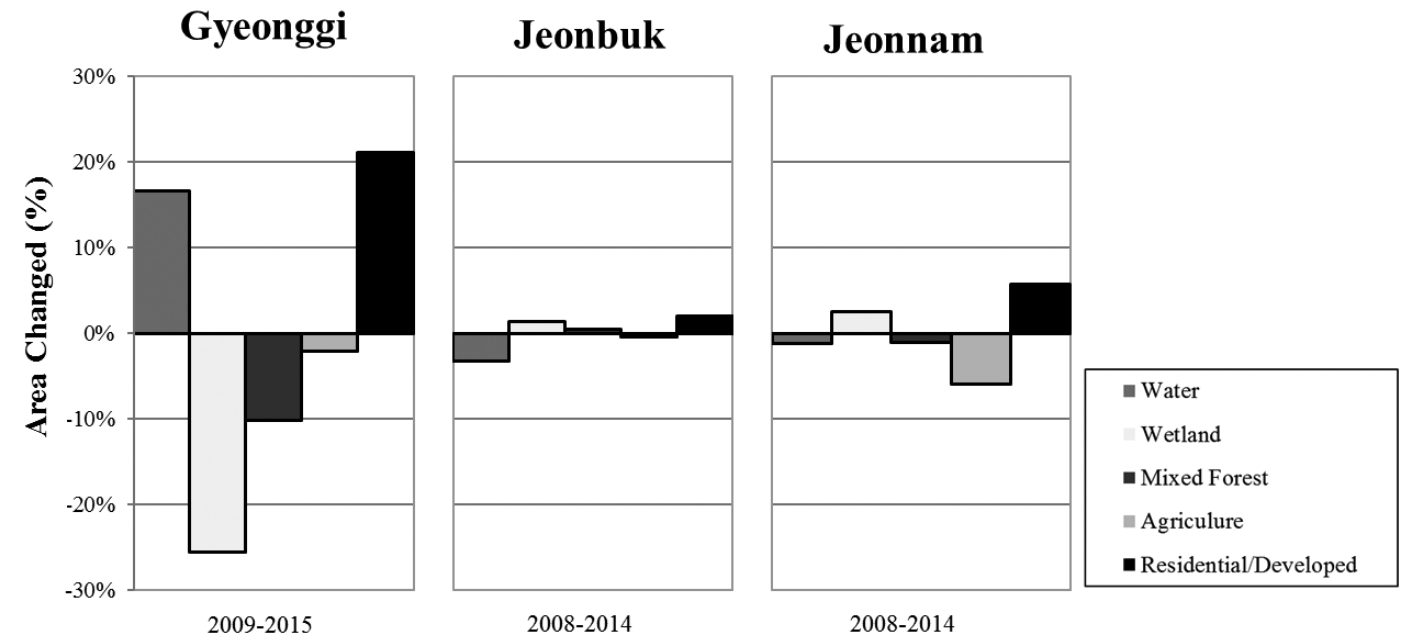

Fig. 4. Comparison of the land use and land cover changes using the spatial distribution pattern over the past five years in each of the three selected regions. The Gyeonggi region represents more noticeable changes in land use and land cover relative to the others. Increases in areas of the residential/developed class in all regions show that population and urban growth has affected the coastal zone significantly. 
environmental effects occurred during this 5-year period, such as economic trends and population growth, which affect land use change. Agriculture and developed areas were dominant in Jeonnam and showed an average combined change of $5.8 \%$. Agricultural land occupied $\sim 22.4$ and $\sim 16.4 \%$ of the total area in 2008 and 2014, respectively, whereas the corresponding values for developed land were $\sim 7.4$ and $\sim 13.2 \%$.

We examined the relationships between population growth and land cover changes, using published reports on population and growth rate data from 1980 to 2010 (Korean Statistical Information Service 2010, http://kosis.kr/). The Gyeonggi regions shows a rapid increase in population. The population of Jeonbuk and Jeonnam shows a decrease (Fig. 5). The total population in Gyeonggi in 2010 was six times more than that of Jeonbuk and Jeonnam, and a significantly higher population growth rate was evident (Table 5). It is considered that the expansion patterns of developed areas reflected industrial development, as changes to the proportion of residential land cover over the studied time period were $21.11 \%$ in Gyeonggi, $1.95 \%$ in Jeonbuk, and $5.77 \%$ in Jeon- nam. The Korean National Statistics Office determined an average population growth rate from 1980 to 2010 was 1.03 in Gyeonggi, 0.99 in Jeonbuk, and 0.97 in Jeonnam (Table 5). Population growth and urban development thus appear to be the primary factors driving the artificial conversion of wetlands. Additionally, in 1987, the Shihwa Reclamation Project was commenced to create agricultural land, urban areas, and industrial complexes in wetland regions. Reclamation projects for urban development transform rural areas (agriculture, forest, and bare soil) into urban areas (Hasse and Lathrop 2003; Potere et al. 2009). Reclamation project continue to be undertaken in Gyeonggi towards building the city. Coastal wetland continue to evolve not only in tidal areas, but also in the regions undergoing developments such as large-scale reclamation and urbanization. However, results showed that Jeonbuk and Jeonnam have undergone a considerable population decrease and a slow rate of land cover change. Both regions have experienced a low rate of population growth, which is likely because they have different geographical characteristics to metropolitan regions. In

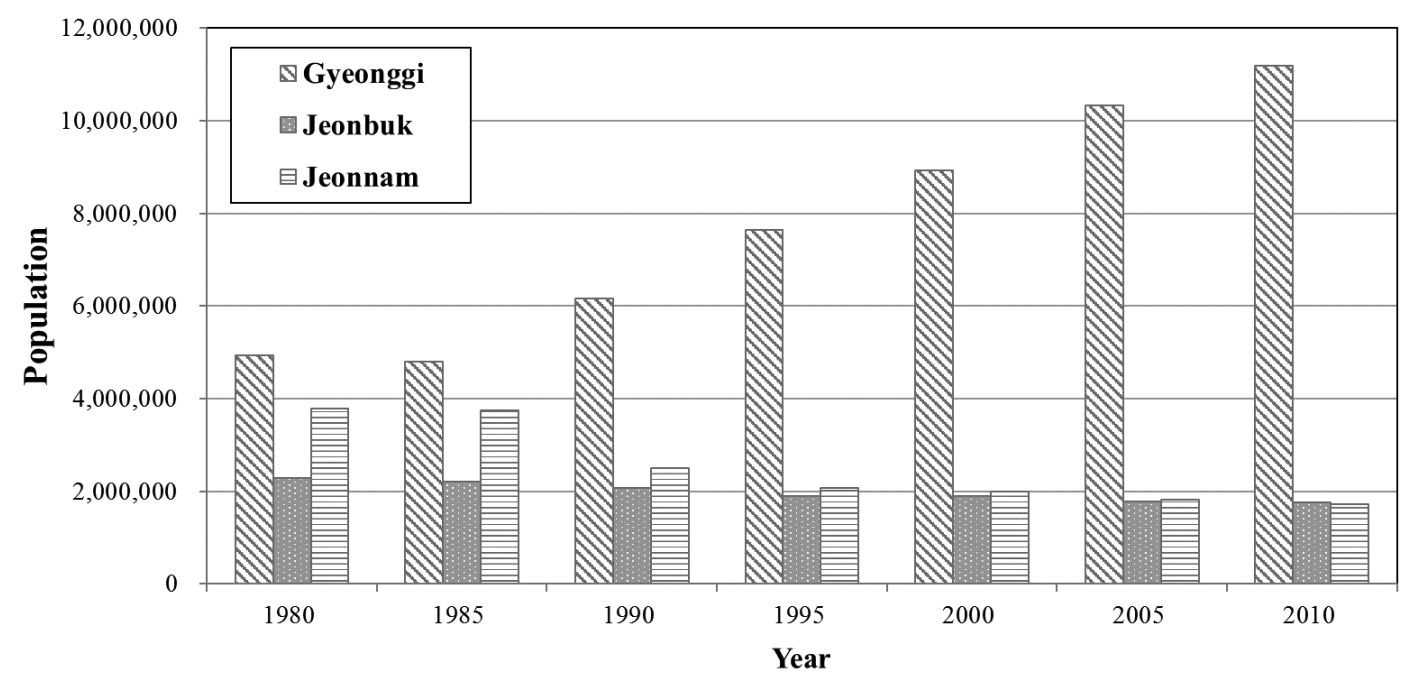

Fig. 5. Population change from 1980 to 2010 five-year growth rates for each study areas. The Gyeonggi regions shows a rapid increase in population. The population of Jeonbuk and Jeonnam shows a decrease.

Table 5. Population change and comparison of five-year growth rates for each of the three study areas.

\begin{tabular}{c|ccccccc}
\hline \multirow{2}{*}{ Area } & \multicolumn{7}{|c}{ Total population (population growth rate) } \\
\cline { 2 - 8 } & $\mathbf{1 9 8 0}$ & $\mathbf{1 9 8 5}$ & $\mathbf{1 9 9 0}$ & $\mathbf{1 9 9 5}$ & $\mathbf{2 0 0 0}$ & $\mathbf{2 0 0 5}$ & $\mathbf{2 0 1 0}$ \\
\hline \multirow{2}{*}{ Gyeonggi } & 4930335 & 4792617 & 6154359 & 7637942 & 8937752 & 10341006 & 11196053 \\
& & $(0.99)$ & $(1.05)$ & $(1.04)$ & $(1.03)$ & $(1.03)$ & $(1.02)$ \\
\hline \multirow{2}{*}{ Jeonbuk } & 2286720 & 2201265 & 2069378 & 1900558 & 1887239 & 1778879 & 1766044 \\
& & $(0.99)$ & $(0.99)$ & $(0.98)$ & $(1.00)$ & $(0.99)$ & $(1.00)$ \\
\hline \multirow{2}{*}{ Jeonnam } & 3778777 & 3747506 & 2506944 & 2066109 & 1994287 & 1815174 & 1728749 \\
& & $(1.00)$ & $(0.92)$ & $(0.96)$ & $(0.99)$ & $(0.98)$ & $(0.99)$ \\
\hline
\end{tabular}


addition, the tidal flats (Julpoman, Gochang, and Jeongdo) located in the two regions have been recognized as wetland areas that are of ecological importance. In 2006, the Ministry of Environment implemented a policy relating to societal and environmental problems arising from development projects in Jeonbuk and Jeonnam. Therefore, although modernization affected the development of agricultural and mixed forest areas, the coastal wetlands did not experience much change.

\section{DISCUSSION}

The greatest changes occurred in wetland and residential/developed categories from 2009 to 2015 in the Gyeonggi area. The wetland class decreased by $20 \%$, while the residential/developed class increased, implying that agriculture and mixed forest land-use types were converted into residential/developed areas (Fig. 3a). Field mapping reveals that development and urbanization led to a decrease in the areal extent of wetland and mixed forest. It is worth noting that unsupervised classification was useful for verifying land-use change using high-resolution satellite images such as KOMPSAT. It can be inferred that the growth of developed areas, which has caused land use change, relates to urban expansion in a positive economic environment ( $\mathrm{Po}$ tere et al. 2009; Zhao et al. 2010). To enable appropriate urban planning, it is necessary to firstly collect data relating to population growth, urban use, and wetland change (Ahmad and Lakhan 2012). This is particularly important for determining how LULC changes affect environmental management and urban development. The condition of the environment, including regions of natural wetland, is closely related to human activities. These data prove that population growth and urbanization have the strongest effect on LULC changes. The areas of mixed forest in Jeonbuk and Jeonnam were similar, although the images were acquired in autumn (October) and summer (August) in Jeonbuk, and spring (April) and winter (January) in Jeonam (Figs. 3a, b). This indicates that the effects of seasonal differences are insignificant compared to external driving factors such as urbanization and land reclamation.

High OA and $\mathrm{K}_{\text {hat }}$ values for the Gyeonggi, Jeonbuk, and Jeonnam images indicate the potential of applying high spatial resolution KOMPSAT imagery to LULC classification, even when using an unsupervised approach (Table 4). Although generally reliable, the classification procedure provided poor classification accuracy for residential regions, which may be the result of highly heterogeneous urban areas distribution and sub-pixel mixing of land cover types because the spectra of objects can have similar properties due to atmospheric and topographic effects (Foody 2000). In addition, spectral inseparability is a major factor contributing to misclassification in residential areas when using KOMPSAT images with a four-band composition. Nevertheless, the accuracy of wetland classification was likely due to its homogeneous distribution in the analyzed images, which indicates the effectiveness of using this technique in wetland change detection along the shoreline of the Yellow Sea.

Matrices showing overall LULC changes in Gyeonggi from 2009 to 2015, in Jeonbuk from 2009 to 2014, and in Jeonnam from 2008 to 2014 are shown in Table 6. Classified LULC changes were defined based on differences in the numbers of pixels between each acquisition date. Table 6 a shows that $2 \mathrm{~km}^{2}$ of water was converted to wetland and mixed forest between 2009 and 2015. In Jeonbuk, a total area of $6.15 \mathrm{~km}^{2}$ of water was converted to wetland, mixed forest, agriculture, and developed areas between 2009 and 2014. Reflectance values (including those for water components) are generally classified as water, although when sea waves surge into wetland along a coastal line, the associated pixels may be erroneously classified as mixed forest or wetland. This is supported by the fact that observations of changes from water to wetland and/or mixed forest almost always occurr near wetland boundaries. In addition to this tidal effect, identification errors may also cause other unusual classification changes. For example, between 2008 and 2015, developed areas in Jeonnam covering 2.8 and $3.9 \mathrm{~km}^{2}$ seemingly changed to areas of mixed forest and agriculture, respectively. It is considered that such changes are most likely to be associated with omission errors in the KOMPSAT- 2 change map classification, or processing errors and edge effects.

Coastal wetlands provide critical ecological services; they play an important role in storing terrestrial carbon and are a habitat for marine and terrestrial life. Although the Ramsar Convention was signed in 1971 to promote the conservation and sustainable use of wetlands, they have since been drained or transformed for various reasons throughout the world. Urbanization is most likely the major cause of wetlands destruction. Lee et al. (2006) and Patenaude et al. (2015) reported that urbanization exerts significant influences on wetland ecological functions and quality. A rapid reduction of approximately $20 \%$ over the 6 -year period occurred in coastal wetland regions in Gyeonggi (close to urban areas); raising a need for systematic monitoring in the future to enable a comparison between changes in Jeonnam and Jeonbuk. LULC classification using KOMPSAT images shows the potential of enabling wetland mapping and monitoring, as well as defining wetland regions using the means of remote sensing. KOMPSAT images with high classification accuracies could be applied to other wetlands that have not been previously monitored using high-resolution remote sensing images.

\section{CONCLUSIONS}

High OA and $\mathrm{K}_{\text {hat }}$ values were retrieved from KOMPSAT-2 images of three regions (Gyeonggi, Jeonbuk, and Jeonnam) taken between 2008 and 2015. These results 
Table 6. Matrices of land use and land cover changes $\left(\mathrm{km}^{2}\right)$ at each of the three study areas.

(a) Gyeonggi

\begin{tabular}{c|cccccc}
\hline \multirow{2}{*}{2009} & \multicolumn{5}{|c}{$\mathbf{2 0 1 5}$} \\
\cline { 2 - 7 } & Water & Wetland & Mixed Forest & Agriculture & Residential/Developed & Total area \\
\hline Water & 0.00 & 1.54 & 1.11 & 0.92 & 2.58 & 6.15 \\
Wetland & 27.65 & 0.00 & 3.04 & 2.38 & 7.44 & 40.51 \\
Mixed Forest & 1.70 & 4.42 & 0.00 & 4.45 & 10.90 & 21.46 \\
Agriculture & 1.49 & 2.76 & 3.06 & 0.00 & 8.99 & 16.30 \\
Residential/Developed & 0.52 & 2.04 & 4.46 & 3.47 & 0.00 & 10.50 \\
\hline Total area & 31.36 & 10.76 & 11.67 & 11.22 & 29.91 & \\
\hline (b) Jeonbuk & & & & & & \\
\hline \multirow{2}{*}{$\mathbf{2 0 0 9}$} & & & & $\mathbf{2 0 1 4}$ & & \\
\cline { 2 - 7 } & Water & Wetland & Mixed Forest & Agriculture & Residential/Developed & Total area \\
\hline Water & 0.00 & 0.92 & 1.07 & 1.90 & 3.13 & 7.02 \\
Wetland & 22.11 & 0.00 & 4.43 & 3.17 & 9.63 & 39.33 \\
Mixed Forest & 1.94 & 3.29 & 0.00 & 4.08 & 9.93 & 19.24 \\
Agriculture & 1.58 & 1.53 & 2.09 & 0.00 & 4.15 & 9.35 \\
Residential/Developed & 0.00 & 0.00 & 0.00 & 0.00 & 0.00 & 0.00 \\
\hline Total area & 25.63 & 5.73 & 7.59 & 9.15 & 26.84 & \\
\hline
\end{tabular}

\begin{tabular}{c|cccccc}
\hline \multicolumn{1}{c|}{ (c) Jeonnam } & \multicolumn{7}{c}{$\mathbf{2 0 1 4}$} \\
\hline \multirow{2}{*}{$\mathbf{2 0 0 8}$} & Water & Wetland & Mixed Forest & Agriculture & Residential/Developed & Total area \\
\cline { 2 - 7 } & 0.00 & 12.50 & 1.79 & 1.84 & 2.44 & 18.58 \\
Water & 12.05 & 0.00 & 3.14 & 3.07 & 2.76 & 21.02 \\
Wetland & 1.15 & 3.36 & 0.00 & 8.84 & 4.45 & 17.80 \\
Mixed Forest & 2.10 & 6.97 & 7.94 & 0.00 & 12.02 & 29.03 \\
Agriculture & 0.94 & 3.03 & 2.82 & 3.95 & 0.00 & 10.74 \\
Residential/Developed & 16.24 & 25.86 & 15.69 & 17.71 & 21.67 & \\
\hline Total area & & & & & &
\end{tabular}

demonstrate that LULC classifications using high spatial resolution KOMPSAT-2 data can be used to produce accurate maps of landscape change and effectively perform change detection analysis. Changing patterns of LULC classification along the coastal boundary of the Korean Peninsula with the Yellow Sea were evaluated by: (1) classifying the proportion of separate land-use types in each region, including coastal wetland, from 2008 to 2015; (2) quantitatively assessing change detection maps; and (3) analyzing the wetland changes in associated with anthropogenic activities and urbanization. The Gyeonggi region showed a decrease in agricultural, mixed forest, and wetland areas over the 5-year study period in relation to an enormous increase in residential/developed areas. Reclamation projects and population growth induced by rapid urbanization resulted in a sudden change in land usage. In contrast, the rates of wetland change in Jeonbuk and Jeonnam were relatively small $(\sim 2$
- 6\%) compared with change in Gyeonggi ( 20\%). Change in land use after 2006 appear to be have been influenced by environmental protection policies adopted to protect coastal wetlands such as those in Jeonbuk and Jeonnam.

This study quantifies land cover change patterns in the coastal zones, with the aim of introducing the use of KOMPSAT-2 imagery and evaluating its application with regard to wetland monitoring. Further studies will attempt to show that high spatial resolution KOMPSAT-2 images have considerable potential to provide accurate and economical mapping of ground conditions. Research into the application of remote sensing to geographical features has led to the development of environmental monitoring data, and reliable LULC classification techniques in coastal zones. Results of such studies are essential for planning the sustainable usage of natural resources and the environment. LULC information derived from KOMPSAT-2 image analysis can also be 
used in efficient coastal management planning, which would subsequently lead to better-informed policy decisions.

Acknowledgements This paper was supported by Samsung Research Fund, Sungkyunkwan University, 2017.

\section{REFERENCES}

Adam, E., O. Mutanga, J. Odindi, and E. M. Abdel-Rahman, 2014: Land-use/cover classification in a heterogeneous coastal landscape using RapidEye imagery: Evaluating the performance of random forest and support vector machines classifiers. Int. J. Remote Sens., 35, 34403458, doi: 10.1080/01431161.2014.903435. [Link]

Ahmad, S. R. and V. C. Lakhan, 2012: GIS-Based analysis and Modeling of Coastline Advance and Retreat Along the Coast of Guyana. Mar. Geodesy, 35, 1-15, doi: 10.1080/01490419.2011.637851. [Link]

Al-doski, J., S. B. Mansor, and H. Z. M. Shafri, 2013: Change detection process and techniques. Civil and Environmental Research, 3, 37-45.

Allen, T. R., Y. Wang, and B. Gore, 2013: Coastal wetland mapping combining multi-date SAR and LiDAR. Geocarto International, 28, 616-631, doi: 10.1080/10106049.2013.768297. [Link]

Anderson, J. R., E. E. Hardy, J. T. Roach, and R. E. Witmer, 1976: A land use and land cover classification system for use with remote sensor data. Professional Paper 964, USGS Publications Warehouse, 28 pp.

Bahadur, K. C., 2009: Improving Landsat and IRS image classification: Evaluation of unsupervised and supervised classification through band ratios and DEM in a mountainous landscape in Nepal. Rem. Sens., 1, 12571272, doi: 10.3390/rs1041257. [Link]

Ball, G. H. and D. J. Hall, 1965: ISODATA, a novel method of data analysis and pattern classification. Technical Report, AD0699616, Stanford Research Institute Menlo Park Califormia.

Baraldi, A., L. Bruzzone, and P. Blonda, 2005: Quality assessment of classification and cluster maps without ground truth knowledge. IEEE Trans. Geosci. Remote Sensing, 43, 857-873, doi: 10.1109/tgrs.2004.843074. [Link]

Braud, D. H. and W. Feng, 1998: Semi-automated construction of the Louisiana coastline digital land/water boundary using Landsat Thematic Mapper satellite imagery. Louisiana Applied Oil Spill Research and Development Program, OS2 RAPD Technical Report Series, 97(002).

Cohen, J., 1960: A coefficient of agreement for nominal scales. Educ. Psychol. Meas., 20, 37-46, doi: 10.1177/001316446002000104. [Link]

Dronova, I., 2015: Object-Based Image Analysis in Wetland Research: A Review. Rem. Sens., 7, 6380-6413, doi: 10.3390/rs70506380. [Link]

Foody, G. M., 2000: Estimation of sub-pixel land cover composition in the presence of untrained classes. Comput. Geosci., 26, 469-478, doi: 10.1016/s00983004(99)00125-9. [Link]

Foody, G. M., 2002: Status of land cover classification accuracy assessment. Remote Sens. Environ., 80, 185201, doi: 10.1016/s0034-4257(01)00295-4. [Link]

Gibbs, J. P., 2000: Wetland loss and biodiversity conservation.Conservat.Biol.,14,314-317, doi: 10.1046/j.15231739.2000.98608.x. [Link]

Gorham, E., 1991: Northern peatlands: Role in the carbon cycle and probable responses to climatic warming. Ecol.Appl., 1, 182-195, doi: 10.2307/1941811. [Link]

Guo, M., J. Li, C. Sheng, J. Xu, and L. Wu, 2017: A review of wetland remote sensing. Sensors, 17, 777, doi: 10.3390/s17040777. [Link]

Hasse, J. E. and R. G. Lathrop, 2003: Land resource impact indicators of urban sprawl. Appl. Geogr., 23, 159-175, doi: 10.1016/j.apgeog.2003.08.002. [Link]

Huang, X. and M. A. Friedl, 2014: Distance metric-based forest cover change detection using MODIS time series. Int. J. Appl. Earth Observation Geoinformation, 29, 78-92, doi: 10.1016/j.jag.2014.01.004. [Link]

Hussain, M., D. Chen, A. Cheng, H. Wei, and D. Stanley, 2013: Change detection from remotely sensed images: From pixel-based to object-based approaches. ISPRS J. Photogram. Rem. Sens., 80, 91-106, doi: 10.1016/j. isprsjprs.2013.03.006. [Link]

Jeong, J., C. Yang, and T. Kim, 2015: Geo-Positioning Accuracy using multiple-satellite images: IKONOS, Quickbird, and KOMPSAT-2 Stereo Images. Rem. Sens., 7, 4549-4564, doi: 10.3390/rs70404549. [Link]

Kassawmar, T., S. Eckert, K. Hurni, G. Zeleke, and H. Hurni, 2016: Reducing landscape heterogeneity for improved land use and land cover (LULC) classification across the large and complex Ethiopian highlands. Geocarto International, 33, 53-69, doi: 10.1080/10106049.2016.1222637. [Link]

Kim, B. K., 1999: An overview of the Korea multi-purpose satellite (KOMPSAT). COSPAR Colloquia Series, Vol. 10, 66-73.

Klemas, V., 2013: Remote sensing of emergent and submerged wetlands: An overview. Int. J. Remote Sens., 34, 6286-6320, doi: 10.1080/01431161.2013.800656. [Link]

Lee, D. S. and J. Shan, 2003: Combining LIDAR elevation data and IKONOS multispectral imagery for coastal classification mapping. Mar. Geodesy, 26, 117-127, doi: 10.1080/01490410306707. [Link]

Lee, S. Y., R. J. K. Dunn, R. A. Young, R. M. Connolly, P. E. R. Dale, R. Dehayr, C. J. Lemckert, S. McKinnon, B. Powell, P. R. Teasdale, and D. T. Welsh, 2006: Impact of urbanization on coastal wetland structure 
and function. Austral Ecology, 31, 149-163, doi: 10.1111/j.1442-9993.2006.01581.x. [Link]

Li, X. and M. C. J. Damen, 2010: Coastline change detection with satellite remote sensing for environmental management of the Pearl River Estuary, China. J. Mar. Syst., 82, S54-S61, doi: 10.1016/j.jmarsys.2010.02.005. [Link]

Lu, D., P. Mausel, E. Brondízio, and E. Moran, 2004: Change detection techniques. Int. J. Remote Sens., 25, 2365-2401, doi: 10.1080/0143116031000139863. [Link]

MacQueen, J., 1967: Some methods for classification and analysis of multivariate observations. In: Le Cam, L. M. and J. Neyman (Eds.), Proceedings of the Fifth Berkeley Symposium on Mathematical Statistics and Probability, Volume 1: Theory of Statistics, University of California Press, 281-297.

Michishita, R., Z. Jiang, P. Gong, and B. Xu, 2012: Bi-scale analysis of multitemporal land cover fractions for wetland vegetation mapping. ISPRS J. Photogram. Rem. Sens., 72, 1-15, doi: 10.1016/j.isprsjprs.2012.04.006. [Link]

Monteys, X., P. Harris, S. Caloca, and C. Cahalane, 2015: Spatial prediction of coastal bathymetry based on multispectral satellite imagery and multibeam data. Rem. Sens., 7, 13782-13806, doi: 10.3390/rs71013782. [Link]

Moser, L., A. Schmitt, A. Wendleder, and A. Roth, 2016: Monitoring of the Lac Bam wetland extent using dualpolarized X-band SAR Data. Rem. Sens., 8, 302, doi: 10.3390/rs8040302. [Link]

Nguyen, H. H., H. Tran, W. Sunwoo, J. Yi, D. Kim, and M. Choi, 2017: Integrated change detection and temporal trajectory analysis of coastal wetlands using high spatial resolution Korean Multi-Purpose Satellite series imagery. J. Appl. Remote Sens., 11, 026030, doi: 10.1117/1.jrs.11.026030. [Link]

Oh, J., C. Lee, and D. C. Seo, 2013: Automated HRSI georegistration using orthoimage and SRTM: Focusing KOMPSAT-2 imagery. Comput. Geosci., 52, 74-84, doi: 10.1016/j.cageo.2012.09.026. [Link]

Ozesmi, S. L. and M. E. Bauer, 2002: Satellite remote sensing of wetlands. Wetlands Ecology and Management, 10, 381-402, doi: 10.1023/A:1020908432489. [Link]
Patenaude, T., A. C. Smith, and L. Fahrig, 2015: Disentangling the effects of wetland cover and urban development on quality of remaining wetlands. Urban Ecosyst., 18, 663-684, doi: 10.1007/s11252-015-0440-1. [Link]

Potere, D., A. Schneider, S. Angel, and D. L. Civco, 2009: Mapping urban areas on a global scale: Which of the eight maps now available is more accurate? Int. J. Remote Sens., 30, 6531-6558, doi: 10.1080/01431160903121134. [Link]

Rapinel, S., L. Hubert-Moy, and B. Clément, 2015: Combined use of LiDAR data and multispectral Earth observation imagery for wetland habitat mapping. Int. J. Appl. Earth Observation Geoinformation, 37, 56-64, doi: 10.1016/j.jag.2014.09.002. [Link]

Rundquist, D. C., S. Narumalani, and R. M. Narayanan, 2001: A review of wetlands remote sensing and defining new considerations. Rem. Sens. Rev., 20, 207-226, doi: 10.1080/02757250109532435. [Link]

Singh, A., 1989: Digital change detection techniques using remotely-sensed data. Int. J. Remote Sens., 10, 9891003, doi: 10.1080/01431168908903939. [Link]

Stroppiana, D., S. Pinnock, J. M. C. Pereira, and J. M. Grégoire, 2002: Radiometric analysis of SPOT-VEGETATION images for burnt area detection in Northern Australia. Remote Sens. Environ., 82, 21-37, doi: 10.1016/ s0034-4257(02)00021-4. [Link]

Tian, J., S. Cui, and P. Reinartz, 2014: Building Change Detection Based on Satellite Stereo Imagery and Digital Surface Models. IEEE Trans. Geosci. Remote Sensing, 52, 406-417, doi: 10.1109/tgrs.2013.2240692. [Link]

Yagoub, M. M. and G. R. Kolan, 2006: Monitoring coastal zone land use and land cover changes of Abu Dhabi using remote sensing. J. Indian Soc. Rem. Sens., 34, 57-68, doi: 10.1007/bf02990747. [Link]

Zhao, M., Z. H. Kong, F. J. Escobedo, and J. Gao, 2010: Impacts of urban forests on offsetting carbon emissions from industrial energy use in Hangzhou, China. J.Environ. Manage., 91, 807-813, doi: 10.1016/j.jenvman.2009.10.010. [Link]

Zhu, Z. and C. E. Woodcock, 2014: Continuous change detection and classification of land cover using all available Landsat data. Remote Sens. Environ., 144, 152171, doi: 10.1016/j.rse.2014.01.011. [Link] 